H 



\title{
Lexikon
}

\section{der englischen}

Wirtschafts- und

Rechtssprache

Band 2:

Deutsch-Englisch

\author{
Von \\ H.-Joerg Salízites \\ Diplom-Übersetzer (Univ.)
}

R. Oldenbourg Verlag München Wien 


\section{Die Deutsche Bibliothek - CIP-Einheitsaufnahme}

\section{Salízites, Hans-Joerg:}

Lexikon der englischen Wirtschafts- und Rechtssprache / von

H.-Joerg Salízites. - München ; Wien : Oldenbourg.

NE : HST

Bd. 2. Deutsch-englisch. - 1994

ISBN 3-486-22715-7

(C) 1994 R. Oldenbourg Verlag GmbH, München

Das Werk einschließlich aller Abbildungen ist uneberrechtlich geschützt. Jede Verwertung außerhalb der Grenzen des Uheberrechtsgesetzes ist ohne Zustimmung des Verlages unzulässig und strafbar. Das gilt insbesondere für Vervielfältigungen, Übersetzungen, Mikroverfilmungen und die Einspeicherung und Bearbeitung in elektronischen Systemen.

Gesamtherstellung: R. Oldenbourg Graphische Betriebe GmbH, München 